\title{
Decentralized Economic Operation Control for Hybrid AC/DC Microgrid
}

Yang, Pengcheng ; Yu, Miao; Wu, Qiuwei; Wang, Peng; Xia, Yanghong ; Wei, Wei

Published in:

IEEE Transactions on Sustainable Energy

Link to article, DOI:

10.1109/TSTE.2019.2946227

Publication date:

2020

Document Version

Peer reviewed version

Link back to DTU Orbit

Citation (APA):

Yang, P., Yu, M., Wu, Q., Wang, P., Xia, Y., \& Wei, W. (2020). Decentralized Economic Operation Control for Hybrid AC/DC Microgrid. IEEE Transactions on Sustainable Energy, 11(3), 1898 - 1910.

https://doi.org/10.1109/TSTE.2019.2946227

\section{General rights}

Copyright and moral rights for the publications made accessible in the public portal are retained by the authors and/or other copyright owners and it is a condition of accessing publications that users recognise and abide by the legal requirements associated with these rights.

- Users may download and print one copy of any publication from the public portal for the purpose of private study or research.

- You may not further distribute the material or use it for any profit-making activity or commercial gain

- You may freely distribute the URL identifying the publication in the public portal 


\title{
Decentralized Economic Operation Control for Hybrid AC/DC Microgrid
}

\author{
Pengcheng Yang, Student Member, IEEE, Miao Yu, Member, IEEE, Qiuwei Wu, Senior Member, \\ IEEE, Peng Wang, Fellow, IEEE, Yanghong Xia, Student Member, IEEE and Wei Wei
}

\begin{abstract}
A hybrid ac/dc microgrid, which consists of alternating current (ac) subgrid(s) and direct current (dc) subgrid(s), can efficiently integrate ac and dc loads, distributed generators (DGs) with minimum conversion stages. The ac and dc subgrids are connected by the bidirectional power converter (BPC) to realize power interaction between them. This paper proposes a decentralized economic operation control for the hybrid ac/de microgrid, which aims to realize economic power sharing among all DGs and economic power interaction between subgrids. For the DGs, the nonlinear droop controls based on ac frequency-incremental cost and dc voltage-incremental cost are proposed, which can equalize DGs' incremental costs autonomously, and hence decrease the subgrids' generation costs with the equal incremental cost principle. For the BPC, the economic power interaction control is proposed to optimize the power interaction between the two subgrids and further decrease the total generation cost (TGC). In addition, the economic operation is categorized into different modes according to the load conditions. The hybrid microgrid with nonlinear incremental cost droops is modeled, and the overall stability analysis is conducted to ensure stable operation in all load conditions and modes. The performance of the proposed control is verified by the real-time hardware-in-loop (HIL) test.
\end{abstract}

Index Terms-- Bidirectional power converter, economic operation, hybrid ac/de microgrid, nonlinear droop control, power interaction.

\section{INTRODUCTION}

W ITH increasing penetration of intermittent renewable energy, critical issues including system stability, reliability, power quality and efficiency have arisen in the power system [1]. By integrating and managing local distributed generators (DGs), energy storage and loads, the microgrid is proposed to deal with the above problems [2]-[4]. The microgrids are mainly the alternating current (ac) type for the advantages such as easy connection with the main power grid. Recently, with the increasing penetration of renewable direct current (dc) DGs and loads such as electric vehicle (EV), LED lighting, IT facilities, etc., the dc microgrid has emerged for its benefits of convenience and low cost [5]-[7]. To facilitate the integration of various types of ac/dc DGs and loads, and reduce unnecessary ac-dc or dc-ac conversions, the hybrid ac/dc microgrid is proposed [8], which can decrease the conversion stages, and thus minimize the energy conversion losses.

The hybrid ac/dc microgrid consists of ac subgrid(s) and dc subgrid(s) which are connected through a bidirectional power

This work is supported in part by the National Key R\&D Program of China(2017YFB0903303)

P. Yang, M. Yu, Y. Xia and W. Wei are with the Zhejiang University, Hangzhou, 310027, China. (e-mail: ypc196@zju.edu.cn, zjuyumiao@zju.edu.cn,royxiayh@126.com,wwei@zju.edu.cn) converter (BPC) as shown in Fig. 1. The subgrid, which contains the same types of ac or dc DGs and loads connected to a common bus, can operate independently as an individual agent, or operate coordinately through the BPC which can manage the power interaction between the two subgrids. There are many studies on the autonomous and coordinated operation of the hybrid microgrid, which aims to improve the reliability and power quality of the system [9], [10]. As the scale of the hybrid microgrid is growing with numerous ac and dc DGs of different cost characteristics, the economic efficiency of the hybrid microgrid need to be improved.

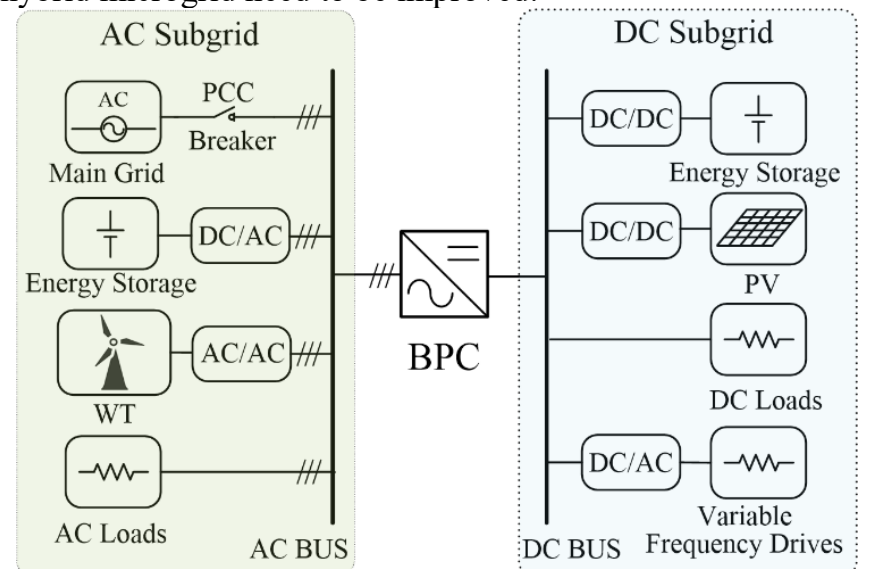

Fig. 1. Topology of the hybrid ac/dc microgrid

In general, the centralized control is adopted to economically optimize the DGs' generation in a microgrid. The microgrid central controller (MGCC) was introduced to acquire every DGs' information, using the optimization algorithms such as mixed-integer programming (MIP) [12] and genetic algorithm [13] minimize the total generation cost (TGC). Based on fast communication and global information, centralized controls have heavy communication burdens and may suffer from a single point of failure. The decentralized control can resolve these problems, which only need local information. However, for the hybrid ac/dc microgrid, the DGs are dispersed in ac and dc subgrids. With only local information, the generation variation of one DG will not affect the DG in the other subgrid unless the power interaction through the BPC can be coordinated accordingly. As such, the decentralized economic operation control of hybrid microgrids is more complicated. In fact, both the economic dispatch between DGs in each individual subgrid and the economic power interaction between subgrids via BPC should be coordinated.

Q. Wu is with the Centre for Electric Power and Energy, Department of Electrical Engineering, Technical University of Denmark, Kgs. Lyngby, 2800, Denmark. (e-mail: qw@elektro.dtu.dk).

P. Wang is with School of Electrical and Electronic Engineering, Nanyang Technological University, 639798, Singapore. (E-mail: epwang@ntu.edu.sg). 
TABLE I

COMPARISON OF CONTROL STRATEGIES

\begin{tabular}{|c|c|c|c|c|c|c|c|c|c|}
\hline \multirow[b]{2}{*}{$\begin{array}{c}\text { Control } \\
\text { Strategies }\end{array}$} & \multicolumn{6}{|c|}{ Economic power sharing control for the DGs in AC and DC subgrids } & \multicolumn{3}{|c|}{ Economic power interaction control for the BPC } \\
\hline & $\begin{array}{l}\text { AC incr- } \\
\text { emental } \\
\text { cost } \\
\text { droop }\end{array}$ & $\begin{array}{l}\text { DC incr- } \\
\text { emental } \\
\text { cost } \\
\text { droop }\end{array}$ & $\begin{array}{c}\text { Consider } \\
\text { the } \\
\text { nonlinear } \\
\text { droop } \\
\text { characteristic }\end{array}$ & $\begin{array}{l}\text { Require } \\
\text { global } \\
\text { information } \\
\text { from all } \\
\text { DGs }\end{array}$ & $\begin{array}{l}\text { Contain } \\
\text { dispat- } \\
\text { chable } \\
\text { energy } \\
\text { storage }\end{array}$ & $\begin{array}{l}\text { Consider the } \\
\text { mode change } \\
\text { and stability } \\
\text { in all load } \\
\text { conditions }\end{array}$ & $\begin{array}{l}\text { Based } \\
\text { on } \\
\text { commu- } \\
\text { nication }\end{array}$ & $\begin{array}{c}\text { Based on } \\
\text { normalized } \\
\text { voltage and } \\
\text { frequency }\end{array}$ & $\begin{array}{c}\text { Based on } \\
\text { equalizing the } \\
\text { ac and dc } \\
\text { subgrids' incre- } \\
\text { mental costs }\end{array}$ \\
\hline Ref.[15] & $\sqrt{ }$ & & $\sqrt{ }$ & & & & & & \\
\hline Ref. $[16]$ & $\sqrt{ }$ & & $\sqrt{ }$ & & & & & & \\
\hline Ref. [17] & & $\sqrt{ }$ & & & $\sqrt{ }$ & & & & \\
\hline Ref. [20] & $\sqrt{ }$ & $\sqrt{ }$ & & $\sqrt{ }$ & & & $\sqrt{ }$ & & \\
\hline Ref. [23] & $\sqrt{ }$ & $\sqrt{ }$ & & $\sqrt{ }$ & & & & $\sqrt{ }$ & \\
\hline $\begin{array}{c}\text { Proposed } \\
\text { Control }\end{array}$ & $\sqrt{ }$ & $\sqrt{ }$ & $\sqrt{ }$ & & & $\sqrt{ }$ & & & $\sqrt{ }$ \\
\hline
\end{tabular}

The decentralized economic dispatch among DGs in a subgrid has been extensively investigated. To reduce the communication burdens and improve the reliability of the microgrid, the hierarchical control strategy, which includes primary, secondary, and tertiary control, was proposed in [14], and only low-bandwidth communication is required to optimize the power generation. To realize no-communication economic power sharing, modified droop schemes considering generation costs were proposed in [15]-[17]. The incremental cost of DG was selected as the consensus variable to manage the generation in the modified droop control. Besides the fuel cost, the emission penalty was taken into account for the TGC calculation in [15]. For DGs with nonlinear generation cost, two linearized cost based droop methods were used in [16], which can facilitate the stability analysis and controller design. In [17], the cost based droop method was developed for the dc microgrid, while only the grid-connected mode is considered. In these cost based droop schemes, the stability is rarely analyzed. However, because the generation costs are usually nonlinear, the stability analysis of the generation cost droop control can be quite different from the traditional linear droop control, so the stability of cost based droop control should be verified.

The economic power interaction between subgrids is another problem for the economic operation of hybrid ac/dc microgrid. The traditional power interaction strategies are mainly focused on the power balance or coordination between subgrids [10], [18]. In [19], a multi-subgrid hybrid microgrid topology was proposed, in which the ac and dc subgrids are connected with a common ac bus, and the particle swarm optimization (PSO) algorithm was used to optimize the power interaction between the subgrids. Ref. [20] proposed a two-level hierarchical optimization method for the hybrid ac/dc microgrid, and a centralized BPC coordination was embedded to regulate the power interaction between subgrids in the upper-layer. By adopting the game theory, an interactive game matrix was defined to mathematically model the power interaction between subgrids in [21], which can use the remaining dispatchable capacity of each subgrid, and thus decrease the operation cost. In [22], a multi-time-scale optimization was employed for three-phase/single-phase hybrid microgrid. By optimizing the power interaction in the day-ahead layer and real-time layer, the TGC is reduced and the unbalance is constrained. The aforementioned strategies are more or less based on the communication between the subgrids, which can increase the communication cost and complicate the microgrid system. In
[23], a totally decentralized economic interaction strategy was proposed by equaling normalized frequency and dc voltage, which worked well in the hybrid ac/dc microgrid without communication. However, the global information from all DGs is required in advance, and only linear incremental cost condition is considered.

In this paper, a decentralized economic operation control is proposed for the hybrid ac/dc microgrid, which can realize the economic dispatch of DGs and minimize the TGC. The comparison between this proposed control method and the existing control method is shown in Table I. The main advantages of the proposed control are summarized as follows:

1) The proposed control strategy is implemented on DGs and BPC in a decentralized way. For the DGs in each subgrids, the nonlinear incremental cost droop control is proposed, which can decrease the subgrids' generation costs autonomously, and only the information from DGs in the local subgrid is needed; For the BPC, an economic power interaction strategy is proposed to manage the power exchange between subgrids, which can equalize the subgrids' incremental cost, and further decrease the TGC.

2) The economic operation process is analyzed and categorized into different modes according to the load conditions. The hybrid microgrid with nonlinear incremental cost droop is modeled, and the overall stability analysis is made to ensure the stable operation in all load conditions and modes.

The rest of this paper is organized as follows. In Section II, the economic operation problem of the hybrid ac/dc microgrid and the equal incremental cost principle are introduced. In Section III, the economic operation control for the ac subgrid, dc subgrid and the economic power interaction control for the $\mathrm{BPC}$ are proposed, respectively. Besides, the economic operation modes are analyzed. In Section IV, the small signal model of the hybrid microgrid system is established to analyze the stability with the proposed control along with different load conditions in each operation mode. In Section V, the HIL tests results are presented to verify the economic efficiency of the proposed control, followed by the conclusions in Section VI.

\section{HYBrid Microgrid ECONOMIC OPERATION PROBLEM}

The economic operation aims to reduce the TGC of the hybrid microgrid which consists of the generation costs of DGs. In this section, the generation costs of different types of DGs are firstly presented. The economic operation problem is defined. The theoretical solution method for the economic operation problem is proposed based on the equal incremental 
cost principle.

\section{A. Total Generation Cost of the Hybrid Microgrid}

The generation cost of a DG is mainly determined by the output active power, while the reactive power cost is relatively small and negligible. Besides, the capital expenditure (CAPEX) costs are not considered in this paper. As such, the generation cost of a DG is its operation cost. Different DGs have different generation cost expressions. In this paper, DGs are categorized into two types, dispatchable DGs and undispatchable DGs. For the dispatchable DGs like diesel generator, micro turbine and fuel cell, the generation cost $C(P)$ includes three parts: the maintenance cost $C_{m}(P)$, the fuel cost $C_{f}(P)$ and the emission penalty $C_{\xi}(P)$. The maintenance cost can be expressed by a liner function, and the fuel cost and emission penalty can be expressed by a quadratic function and an exponential function [24]. The expression of the generation cost of dispatchable DG is

$C(P)=C_{m}(P)+C_{f}(P)+C_{\xi}(P)=\alpha \cdot P^{2}+\beta \exp (\gamma \cdot P)+\delta \cdot P+\epsilon$,

where $\alpha, \beta, \gamma, \delta, \epsilon$ are coefficients of the generation cost.

The undispatchable DGs mainly include renewable energy sources such as photovoltaic and wind turbine, thus the generation does not need to consume fuel and there is no fuel cost. Besides, considering that there is no emission, the emission penalty is set as negative to decrease the generation cost, which can encourage the environmentally friendly generation. In this way, the generation cost of renewable DG is usually less expensive than the dispatchable DG. The expression of the generation cost of undispatchable DG is

$$
C(P)=C_{m}(P)+C_{\xi}(P)=\beta \exp (\gamma \cdot P)+\delta \cdot P+\epsilon .
$$

The TGC of the hybrid microgrid includes all the generation costs of dispatchable DGs and undispatchable DGs in both the ac subgrid and the dc subgrid. The goal of economic operation is to minimize the TGC, which can be expressed as

$$
\begin{aligned}
& \min : T G C=\sum_{i=1}^{M} C_{i}\left(P_{i}\right)+\sum_{j=1}^{N} C_{j}\left(P_{j}\right), \\
& \text { for: } i=1,2, \ldots, M \text { and } j=1,2, \ldots, N,
\end{aligned}
$$

where $\sum_{i=1}^{M} C_{i}\left(P_{i}\right)$ is the TGC of the ac subgrid with $M$ DGs, and $\sum_{j=1}^{N} C_{j}\left(P_{j}\right)$ is the TGC of the de subgrid with $N$ DGs. The expression in (3) denotes that the TGC of the hybrid microgrid is composed by the TGCs of ac subgrid and de subgrid.

The power limits of DGs and the power balance constraints are considered and expressed as follows:

$$
\begin{gathered}
P_{i}^{\text {min }}<P_{i} \leq P_{i}^{\text {max }}, P_{j}^{\text {min }}<P_{j} \leq P_{j}^{\text {max }} \\
\sum_{i=1}^{M} P_{i}+P_{B P C}+P_{G C}=P_{L, a c} \\
\sum_{j=1}^{N} P_{j}-P_{B P C}=P_{L, d c}
\end{gathered}
$$

where $P_{i}^{\max }$ is the generation limit of the $i$-th DG in the ac subgrid, and $P_{j}^{\max }$ is the generation limit of the $j$-th DG in the dc subgrid. $P_{B P C}$ is the power interaction between ac subgrid and de subgrid, and power flows from the de subgrid to the ac subgrid is considered as positive. $P_{G C}$ is the power exchange with the main grid in the grid-connected mode, and it is zero in the islanded mode. $P_{L, a c}$ and $P_{L, d c}$ are the load power of ac and dc subgrids.

\section{B. Equal Incremental Cost Principle}

The economic operation objective in (3) can be realized by utilizing the equal incremental cost principle, which is detailed as follows: When the total generation cost reaches a minimum, the incremental costs of different terminals should be equal to each other or reach their bounds if the transmission capacity is sufficient [24]. The incremental cost of DG is the derivative of generation cost which can expressed as $\mathrm{d} C(P) / \mathrm{d} P$. To be simplified, the incremental cost function $\lambda(P)$ is introduced to denote $\mathrm{d} C(P) / \mathrm{d} P$. In this paper, the transmission capacity is considered sufficient. According to the equal incremental cost principle, if $0<P_{i} \leq P_{i}^{\max }$ and $0<P_{j} \leq P_{j}^{\max }$, the TGC of the hybrid microgrid will be minimal with equation (7) satisfied

$$
\left\{\begin{array}{c}
\text { ac subgrid: } \lambda_{1}\left(P_{1}\right)=\lambda_{2}\left(P_{2}\right)=\cdots=\lambda_{i}\left(P_{i}\right)=\lambda_{a c} \\
\text { dc subgrid: } \lambda_{1}\left(P_{1}\right)=\lambda_{2}\left(P_{2}\right)=\cdots=\lambda_{j}\left(P_{j}\right)=\lambda_{d c}, \\
\lambda_{a c}=\lambda_{d c}
\end{array}\right.
$$

where $\lambda_{i}\left(P_{i}\right)=\mathrm{d} C_{i}\left(P_{i}\right) / \mathrm{d} P_{i}$ is the incremental cost of the $i$-th DG, $\lambda_{a c}$ is defined as the incremental cost of the ac subgrid, and $\lambda_{d c}$ is defined as the incremental cost of the dc subgrid. From (7), it can be seen that the incremental cost of DGs should be identical with the other DGs in the same subgrid, besides, the incremental costs of both subgrids should be equal.

If the output power of DGs reach their limits, the corresponding incremental cost functions are written as follows:

$$
\left\{\begin{array}{l}
\lambda_{i}\left(P_{i}\right) \leq \lambda_{a c}, \quad P_{i}=P_{i}^{\max } \\
\lambda_{j}\left(P_{j}\right) \leq \lambda_{d c}, \quad P_{j}=P_{j}^{\max } .
\end{array}\right.
$$

The incremental costs of undispatchable renewable DGs are usually much lower than the incremental costs of dispatchable DGs, and the output power of renewable DGs usually reach their maximum limits, which means that the renewable DGs should operate in maximum power point tracking (MTTP) mode for economy. Thus, the dispatchable DGs are the main control parameters in this article.

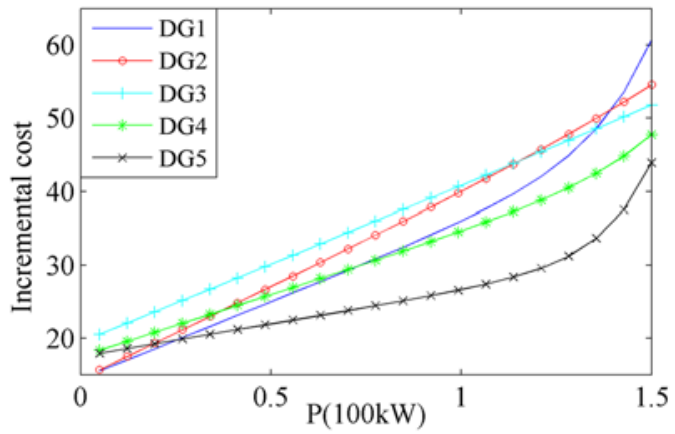

Fig. 2. Incremental costs of DGs

The generation cost function $C(P)$ is mostly convex, so the incremental cost function $\lambda(P)$ is an increasing function as Fig. 2 shows. The DGs' parameters are mainly from the 6-generator, 30-bus system [25], which are listed in Table II. The equation (7) would be easy to realize in the centralized manner. With the fast communication, the incremental costs of all DGs can be available, and $\lambda(P)$ of all DGs can tend towards identical by regulating the corresponding $P$. However, for the hybrid ac/dc microgrid, numerous DGs disperse in both ac and dc subgrids, which can largely complicate the communication networks. In the following, to minimize the TGC of the hybrid ac/dc microgrid, the decentralized control strategy will be studied to realize equation (7) in the Section III. 
TABLE II

COEFFICIENTS OF THE GENERATION COST

\begin{tabular}{cccccccc}
\hline \hline DG $_{i}$ & $\alpha$ & $\beta$ & $\gamma$ & $\delta$ & $\epsilon$ & $\begin{array}{c}P^{\max } \\
(100 \mathrm{~kW})\end{array}$ & $\begin{array}{c}P^{\min } \\
(100 \mathrm{~kW})\end{array}$ \\
\hline DG1 & 10.52 & $1.0 \mathrm{E}-4$ & 6.667 & 14.44 & 1.61 & 1.50 & 0.05 \\
DG2 & 12.56 & $5.0 \mathrm{E}-3$ & 3.333 & 14.40 & 1.25 & 1.50 & 0.05 \\
DG3 & 10.65 & $2.0 \mathrm{E}-3$ & 2.857 & 19.44 & 1.41 & 1.50 & 0.05 \\
DG4 & 8.46 & $1.0 \mathrm{E}-4$ & 6.0 & 17.49 & 2.43 & 1.50 & 0.05 \\
DG5 & 4.46 & $1.0 \mathrm{E}-5$ & 8.0 & 17.49 & 2.43 & 1.50 & 0.05 \\
\hline
\end{tabular}

\section{DeCentralized ECONOMiC Operation CONTROL}

In this section, the economic operation control is firstly presented for ac subgrid and dc subgrid, and then the economic interaction power control is proposed for the BPC. The corresponding control topologies are also given for each control strategy. As a result, the economic operation of hybrid ac/dc microgrid can be realized with the proposed control strategies.

\section{A. Economic Operation Control of the AC Subgrid}

In the ac subgrid, the traditional $P-f$ droop control is commonly adopted for decentralized load sharing, which is

$$
f_{i}^{r e f}=f^{*}+m_{i}\left(P_{i}^{*}-P_{i}\right),
$$

where $f_{i}^{\text {ref }}$ is the output reference frequency of $\mathrm{DG}_{i}, f^{*}$ is rated frequency, and $m_{i}=\left(f^{\max }-f^{\min }\right) / P_{i}^{\max }$ is the droop coefficient for $\mathrm{DG}_{i}, f^{\max }$ and $f^{\min }$ are the maximum and minimum frequencies. $P_{i}^{\max }$ is the maximum output power of $\mathrm{DG}_{i}, P_{i}^{*}$ is the rated output power of $\mathrm{DG}_{i}$, and $P_{i}^{*}=0.5 P_{i}^{\max }$. In this paper, it is assumed that the inductive virtual impedance is designed, and bigger than the line impedance. As such, the total equivalent output impedance is dominated by the virtual impedance and inductive [26].

All the DGs share a common frequency in the steady state, which means that the output frequencies $f_{i}^{r e f}$ are identical for all DGs. From (9), the output power of DGs are proportional to their maximum output power. Thus, the power sharing between the DGs is realized in a decentralized way, and the power sharing proportion is only related to the power capacities of DGs, not related to the generation cost, which is not economic.

In this paper, the operation economy is the main concern in load sharing between DGs. According to the equal incremental cost principle in Section II, when the subgrid is under economic operation, the incremental costs of DGs in the ac subgrid should be equal unless their output power reach their limits. Based on this, the incremental cost functions are introduced, and a new frequency-incremental cost $f-\lambda_{a c}$ droop is proposed to realize the decentralized power sharing and economic operation simultaneously. The proposed control for DGs in the ac subgrid is

$$
f_{i}^{r e f}=f^{*}+m\left(\lambda_{a c}^{*}-\lambda_{i}\left(P_{i}\right)\right),
$$

where $\lambda_{a c}^{*}$ is the rated incremental cost of ac subgrid, $m$ is the ac droop coefficient. $\lambda_{a c}^{*}$ and $m$ are given in (11) by considering the range of ac subgrid DGs' incremental cost and frequency. $\lambda_{a c}^{\max }$ is set as the maximum of the ac subgrid DGs' incremental cost, and $\lambda_{a c}^{\min }$ is set as the minimum of the ac subgrid DGs' incremental cost. The power sharing of the frequency-incremental cost droop is shown in Fig.3, whose ordinate is frequency.

$$
\begin{gathered}
\lambda_{a c}^{\max }=\max \left(\lambda_{1}\left(P_{1}^{\max }\right), \lambda_{2}\left(P_{2}^{\max }\right), \ldots, \lambda_{M}\left(P_{M}^{\max }\right)\right), \\
\lambda_{a c}^{\min }=\min \left(\lambda_{1}\left(P_{1}^{\min }\right), \lambda_{2}\left(P_{2}^{\min }\right), \ldots, \lambda_{M}\left(P_{M}^{\min }\right)\right),
\end{gathered}
$$

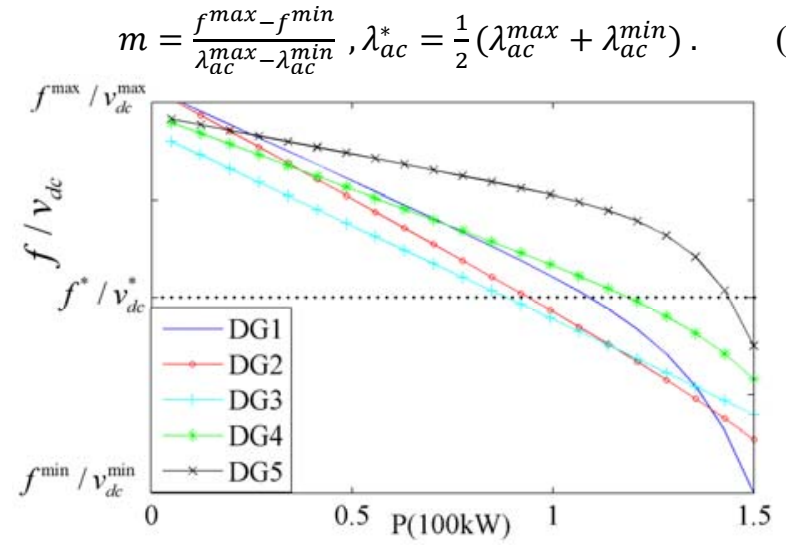

Fig. 3. The economic power sharing of frequency-incremental cost droop control and dc voltage-incremental cost droop control (for DGs in the ac subgrid, the ordinate is frequency; for DGs in the de subgrid, the ordinate is dc voltage)

From (11), $\lambda_{a c}^{*}$ and $m$ are the same for all the DGs in the ac subgrid. In the steady state, the frequency is the same for all DGs, which can guarantee that the incremental costs $\lambda_{i}\left(P_{i}\right)$ of all DGs get identical, and the first expression in (7) is satisfied. According to the equal incremental cost principle, the TGC of ac subgrid is minimal, and the ac subgrid economic operation is realized.

As the reactive power cost is considered free, the traditional $Q-V$ droop control is adopted to generate the reference voltage magnitude as

$$
V_{i}^{r e f}=V^{*}-n_{i}\left(Q_{i}-Q_{i}^{*}\right)
$$

Based on the strategy in (10), (12), the control topology is designed as Fig.4.

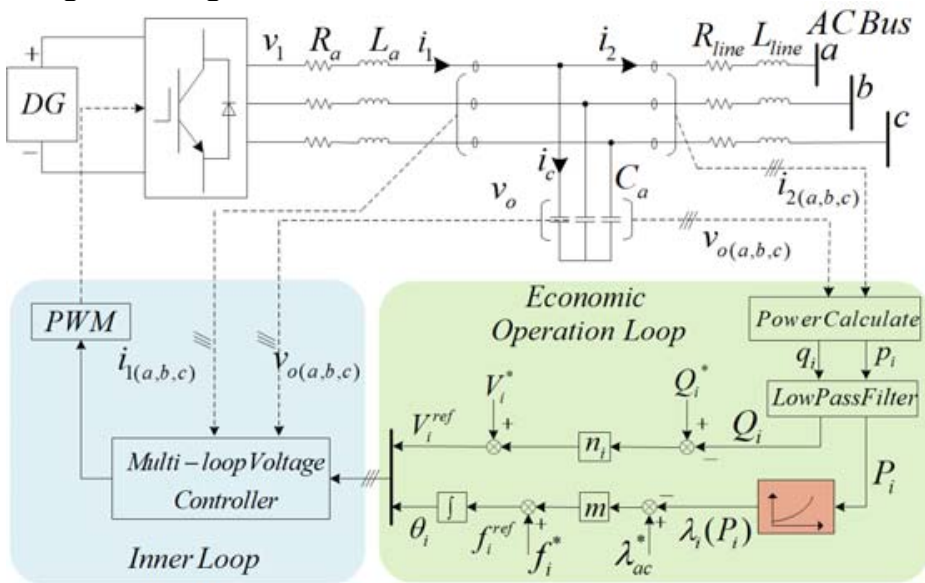

Fig. 4. Control topology of the DG in the ac subgrid

\section{B. Economic Operation Control of the DC Subgrid}

In the dc subgrid, the $P-v_{d c}$ droop control is commonly used for dc load sharing which is expressed as

$$
v_{d c, j}^{r e f}=v_{d c}^{*}+w_{j}\left(P_{j}^{*}-P_{j}\right),
$$

where $v_{d c, j}^{r e f}$ is the output reference dc voltage of $\mathrm{DG}_{j}, v_{d c}^{*}$ is rated dc voltage, and $w_{j}=\left(v_{d c}^{\max }-v_{d c}^{\min }\right) / P_{j}^{\max }$ is the droop coefficient for $\mathrm{DG}_{j}, v_{d c}^{\max }$ and $v_{d c}^{\min }$ are the maximum and minimum allowable dc voltages, $P_{j}^{*}$ is the rated output power of $\mathrm{DG}_{j}$, and $P_{j}^{*}=0.5 P_{j}^{\max }$.

In the dc subgrid, the voltage drop caused by the de line impedance will result in dc bus voltage deviation, and influence the power sharing. Comparing with the voltage deviation 
caused by the droop control, the voltage drop caused by the line impedance is tiny and can be neglected. Therefore, the dc bus voltage can be viewed as a globe state, and the output dc voltage $v_{d c, j}^{r e f}$ can be viewed as identical for all DGs in the steady state. Similar to the $f-\lambda_{a c}$ droop control, the dc voltageincremental cost droop $v_{d c}-\lambda_{d c}$ is designed and expressed as

$$
v_{d c, j}^{r e f}=v_{d c}^{*}+w\left(\lambda_{d c}^{*}-\lambda_{j}\left(P_{j}\right)\right)
$$

where $\lambda_{d c}^{*}$ is the rated incremental cost of dc subgrid, $w$ is the $\mathrm{dc}$ droop coefficient. Both parameters are given in (15) by considering the range of dc subgrid DGs' incremental cost and dc voltage. $\lambda_{d c}^{\max }$ is set as the maximum of the dc subgrid DGs' incremental cost, and $\lambda_{d c}^{\min }$ is set as the minimum of the dc subgrid DGs' incremental cost. The power sharing of the dc voltage-incremental cost droop is shown in Fig.3, whose ordinate is de voltage.

$$
\begin{gathered}
\lambda_{d c}^{\max }=\max \left(\lambda_{1}\left(P_{1}^{\max }\right), \lambda_{2}\left(P_{2}^{\max }\right), \ldots, \lambda_{N}\left(P_{N}^{\max }\right)\right), \\
\lambda_{d c}^{\min }=\min \left(\lambda_{1}\left(P_{1}^{\min }\right), \lambda_{2}\left(P_{2}^{\min }\right), \ldots, \lambda_{N}\left(P_{N}^{\min }\right)\right), \\
w=\frac{v_{d c}^{\max }-v_{d c}^{\min }}{\lambda_{d c}^{\max }-\lambda_{d c}^{\min }}, \lambda_{d c}^{*}=\frac{1}{2}\left(\lambda_{d c}^{\max }+\lambda_{d c}^{\min }\right) .
\end{gathered}
$$

From (14), $\lambda_{d c}^{*}$ and $w$ are the same for all the DGs in the $\mathrm{dc}$ subgrid. In the steady state, the dc voltage is the same for all DGs, which can ensure that the incremental costs $\lambda_{j}\left(P_{j}\right)$ of all DGs are identical, and the second expression in (7) is satisfied. According to the equal incremental cost principle, the dc subgrid is under economic operation with the proposed control in (14).

\section{Economic Interaction Power Control for the BPC}

In this subsection, the power interaction between two subgrids is our main concern, which is realized by BPC. By adopting the proposed $f-\lambda_{a c}$ and $v_{d c}-\lambda_{d c}$ droop control, the two subgrids can economically operate, individually. To realize the overall economic operation of the hybrid ac/dc microgrid, the third equation in (7) is essential and the two subgrids' incremental costs need to be equal. The BPC can manage the power interaction between the two subgrids, consequently, change the total power generations in two subgrids and balance the two subgrids' incremental costs.

The incremental cost of ac subgrid $\lambda_{a c}$ can be obtained by (7), (10), which is expressed as

$$
\lambda_{a c}=\lambda_{a c}^{*}+\frac{1}{m}\left(f^{*}-f\right)
$$

where $\lambda_{a c}^{*}, m, f^{*}$ are the defined parameters of ac subgrid, and the ac frequency $f$ is measurable by local sensors of BPC. In this way, $\lambda_{a c}$ can be obtained in a decentralized manner.

Similar to the ac incremental cost, the de incremental cost $\lambda_{d c}$ can be obtained by (7), (14), which is given by

$$
\lambda_{d c}=\lambda_{d c}^{*}+\frac{1}{w}\left(v_{d c}^{*}-v_{d c}\right)
$$

where $\lambda_{d c}$ is also obtained in a decentralized manner.

An effective method to ensure $\lambda_{a c}=\lambda_{d c}$ is to feed their difference to a proportional-integral (PI) controller. The output of PI controller is set as the interaction power between two subgrids. By changing the interaction power, the total power generations of the two subgrids will change according to the power balance in (5), (6), which can alter the two incremental costs, and make them tend to equal. In this way, the control method for BPC is given as

$$
P_{B P C}=\left(k_{P}+k_{I} / s\right)\left(\lambda_{a c}-\lambda_{d c}\right)
$$

$k_{P}, k_{I}$ are the proportional parameter and integral parameter of PI controller. The control topology is designed as Fig. 5.

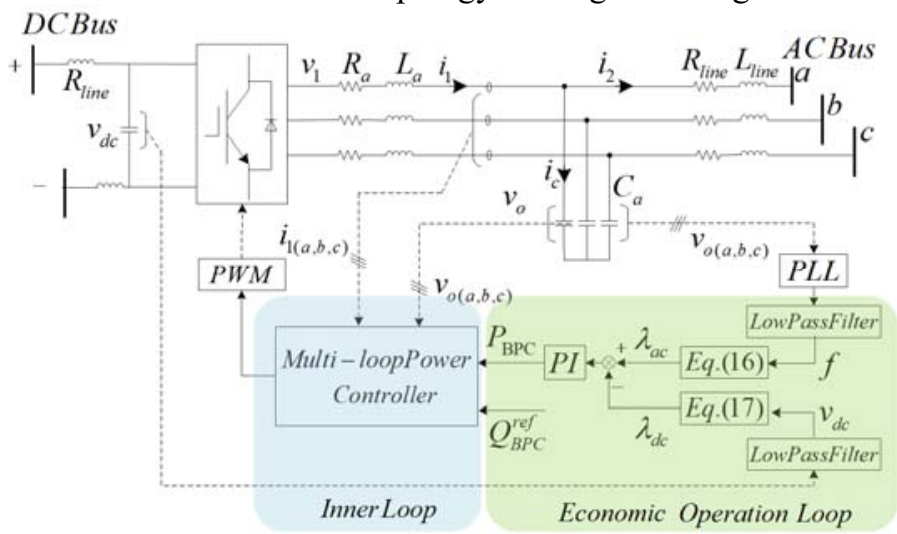

Fig. 5. Control topology of the BPC in the hybrid ac/dc microgrid

D. Economic Operation of the Hybrid AC/DC Microgrid

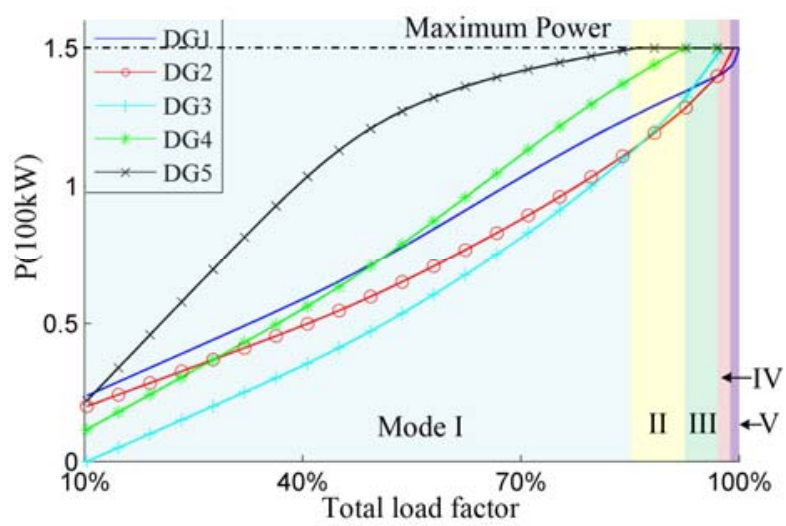

Fig. 6. Economic power dispatch for DGs. Mode I: no DG reaches the maximum power. Mode II: DG5 reaches the maximum power. Mode III: DG4, DG5 reach the maximum power. Mode IV: DG3, DG4, DG5 reach the maximum power. Mode V: DG2, DG3, DG4, DG5 reach the maximum power.

By adopting the proposed economic operation control, the power will be shared according to DGs' incremental costs. For the DG with lower incremental cost, more power will be shared by this DG to reduce the TGC, consequently, this DG will reach its maximum power firstly. For the DGs in Fig.2, the DG5 will reach the maximum power of $150 \mathrm{~kW}$ firstly with the increasing of the load power, and then DG4 will reach the maximum power, and the next sequence is DG3, DG2 and DG1. With the increasing of load power, the economic power dispatch for DGs is shown in Fig.6. Different modes are utilized to indicate DGs operation status. In mode I, all DGs operate in incremental cost droop control mode, and no DG reaches the maximum power. In mode II, DG5 reaches the maximum power and the remaining DGs share the increased load power. The DG4, DG3, DG2 reach the maximum power in Mode III, Mode IV and Mode V, correspondingly. When the DG reaches the maximum power, it will be undispatchable, hence the load fluctuation will be shared by the remaining DGs, which may endanger the stability of the system. The detailed stability analysis of different modes will be carried out in section IV.

The power interaction for BPC can be depicted in Fig. 7. For the hybrid microgrid in Fig. 11(a), according to the different load factors in ac and dc subgrid, the interaction power will be transferred via BPC to equal the two subgrids' incremental 
costs, and to further decrease the TGC. The economic operation of the hybrid AC/DC microgrid can be realized.

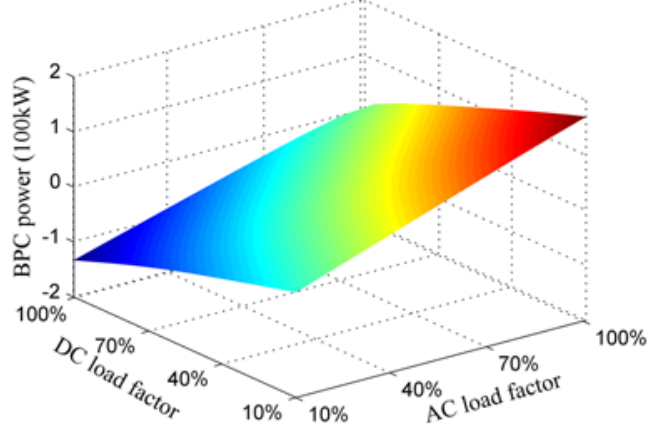

Fig. 7. Economic power interaction for BPC with different ac and de load factors.

\section{STABILITY ANAlysis OF HYbrid AC/DC MiCROGRID}

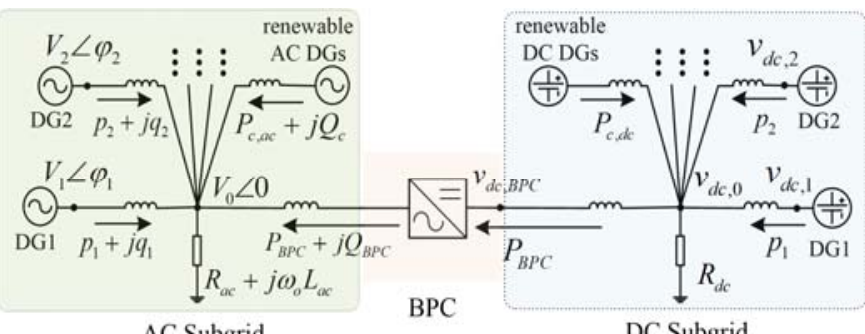

Fig. 8. Simplified topology of the hybrid ac/dc microgrid

In this section, the stability of the hybrid microgrid with the proposed economic operation control method of Section III is analyzed in islanded mode. To simplify the modeling of the system, the ac loads and dc loads are characterized by the impedances $R_{a c}+j \omega_{0} L_{a c}$ and $R_{d c}$. The renewable DGs operate in the MPPT mode, and their total output powers are supposed to be invariable in the dynamic process, which are respectively $P_{c, a c}+j Q_{c}$ and $P_{c, d c}$ as shown in Fig. 8. Section XIII (Appendix) shows the specify matrix definition in this section.

\section{A. AC Subgrid Model}

In the ac subgrid, the line impedance of $\mathrm{DG}_{i}$ is $R_{l i}+j \omega_{i} L_{l i}$. The ac bus voltage is set as the common reference voltage denoted as $V_{0} \angle 0$. The phase $\varphi_{i}$ and magnitude $V_{i}$ of the $i$-th DG's voltage $V_{i} \angle \varphi_{i}$ satisfies

$$
\begin{aligned}
\dot{\varphi}_{i} & =\omega_{i}-\omega_{0}=2 \pi \cdot f_{i}-2 \pi \cdot f_{0} \\
\varphi_{i} & =\arctan \left(\frac{V_{q i}}{V_{d i}}\right) \\
V_{i} & =\sqrt{V_{d i}^{2}+V_{q i}^{2}}
\end{aligned}
$$

where $f_{0}$ is the frequency of the common ac bus voltage, which is considered to be invariable in the small signal analysis. Linearizing (20), (21), (22), we get

$$
\begin{gathered}
\Delta \dot{\varphi}_{i}=\Delta \omega_{i}=2 \pi \cdot \Delta f_{i} \\
\Delta \varphi_{i}=k_{d i} \Delta V_{d i}+k_{q i} \Delta V_{q i} \\
\Delta V_{i}=l_{d i} \Delta V_{d i}+l_{q i} \Delta V_{q i} \\
k_{d i}=\frac{-V_{q i}}{V_{d i}^{2}+V_{q i}^{2}}, k_{q i}=\frac{V_{d i}}{V_{d i}^{2}+V_{q i}^{2}}, l_{d i}=\frac{V_{d i}}{\sqrt{V_{d i}^{2}+V_{q i}^{2}}}, l_{q i}=\frac{V_{q i}}{\sqrt{V_{d i}^{2}+V_{q i}^{2}}}
\end{gathered}
$$

The dynamic of multi-loop voltage controller in Fig. 4 is much faster than economic control loop. Thus, the transfer function of multi-loop voltage controller can be simplified as ' 1 ', which means that $\mathrm{DG}_{i}$ frequency $f_{i}$ and magnitude $V_{i}$ satisfy $f_{i}=f_{i}^{r e f}, V_{i}=V_{i}^{r e f}$ in expression (10), (12). Linearizing (10), (12),

$$
\begin{aligned}
& \Delta f_{i}=-m \cdot \frac{d \lambda_{i}\left(P_{i}\right)}{d P_{i}} \Delta P_{i} \\
& \Delta V_{i}=-n_{i} \Delta Q_{i}
\end{aligned}
$$

The feedback $P_{i}$ and $Q_{i}$ are filtered by low-pass filters whose cutoff frequencies are $\omega_{a c}$, and expressed as

$$
P_{i}=\frac{\omega_{a c}}{s+\omega_{a c}} p_{i}, Q_{i}=\frac{\omega_{a c}}{s+\omega_{a c}} q_{i}
$$

where $p_{i}, q_{i}$ are the output instantaneous active power and reactive power of $\mathrm{DG}_{i}$ given by

$$
p_{i}=3 / 2 \cdot\left(V_{d i} \cdot i_{d i}+V_{q i} \cdot i_{q i}\right), q_{i}=3 / 2 \cdot\left(V_{q i} \cdot i_{d i}-V_{d i} \cdot i_{q i}\right)
$$

where $i_{d i}$ and $i_{q i}$ are the output current of $\mathrm{DG}_{i}$, which can be expressed by difference equation (30), (31)

$$
\begin{aligned}
& L_{l i} i_{d i}^{\dot{i_{i}}}=V_{d i}-V_{0}-R_{l i} \cdot i_{d i}+\omega_{i} L_{l i} \cdot i_{q i} \\
& L_{l i} i_{q i}^{{ }_{i}}=V_{q i}-R_{l i} \cdot i_{q i}-\omega_{i} L_{l i} \cdot i_{d i}
\end{aligned}
$$

Linearizing the equation (28)-(31), and combining the linearized equation (23)-(27), the small signal model of the $\mathrm{DG}_{i}$ is obtained

$$
\dot{X}_{D G i}=M_{i} X_{D G i}+N_{i} \Delta V_{0}
$$

$X_{D G i}=\left[\Delta \omega_{i}, \Delta V_{d i}, \Delta V_{q i}, \Delta i_{d i}, \Delta i_{q i}\right]$, Considering the power balance of the ac subgrid, we have

$$
\sum_{i=1}^{M} p_{i}+P_{c, a c}+P_{B P C}=3 / 2 \cdot V_{0}^{2} \cdot R_{a c} /\left(R_{a c}{ }^{2}+\omega_{0}{ }^{2} L_{l i}{ }^{2}\right)
$$

Linearizing (33), and combining the single $\mathrm{DG}_{i}$ model in (32), the small signal model of ac subgrid is derived as

$$
\dot{X}_{A C}=P X_{A C}+Q \triangle P_{B P C}
$$

where $X_{A C}=\left[X_{D G 1}, \cdots, X_{D G i}, \cdots\right]_{1 \times 5 M}{ }_{T}$.

\section{B. DC Subgrid Model}

In the dc subgrid, the line impedance of $\mathrm{DG}_{j}$ is $r_{j}$, The dc bus voltage is denoted as $v_{d c, 0}$, and the output dc voltage of $\mathrm{DG}_{j}$ is denoted as $v_{d c, j}$. The transfer function of dc multi-loop voltage controller is viewed as ' 1 ', which means $v_{d c, j}=v_{d c, j}^{r e f}$ in (14). Linearizing (14), we have

$$
\Delta v_{d c, j}=-w \cdot \frac{d \lambda_{j}\left(P_{j}\right)}{d P_{j}} \Delta P_{j},
$$

The output power $P_{j}$ of dc $\mathrm{DG}_{j}$ is filtered by a low-pass filter whose cutoff frequency is $\omega_{d c}$, and written as

$$
P_{j}=\frac{\omega_{d c}}{s+\omega_{d c}} p_{j}
$$

where $p_{j}$ is the output instantaneous power of $\mathrm{DG}_{j}$. According to the instantaneous power balance of dc subgrid, we have

$$
\sum_{j=1}^{N} p_{j}+P_{c, d c}-P_{B P C}=\frac{v_{d c, 0}^{2}}{R_{d c}}
$$

The dc network relation is expressed as

$$
v_{d c, j}-v_{d c, 0}=\frac{p_{j}}{v_{d c, j}} r_{j}
$$

Linearizing the equation (36)-(38), and combining the linearized equation (35), the small signal mode of dc subgrid is gotten as

with $X_{D C}=\left[\Delta P_{1}, \cdots, \Delta P_{j}, \cdots\right]_{1 \times N} \dot{X}_{D C}=S X_{D C}+T \Delta P_{B P C}$

\section{BPC Model}

For the $\mathrm{BPC}$, the interaction power $\triangle P_{B P C}$ is the input variable of ac subgrid and dc subgrid. According to the expression of $P_{B P C}$ in (16)-(18), the linearized equation of interaction power is gotten as 


$$
\Delta P_{B P C}=\left(k_{P}+k_{I} / s\right)\left(\frac{\Delta v_{d c}}{w}-\frac{\Delta f}{m}\right)
$$

where $\Delta v_{d c}$ and $\Delta f$ are filtered by the dc voltage filter and ac frequency filter whose cutoff frequencies are $\omega_{v d c}$ and $\omega_{f}$, respectively, and written as

$$
v_{d c}=\frac{\omega_{v d c}}{s+\omega_{v d c}} v_{d c, B P C}, f=\frac{\omega_{f}}{s+\omega_{f}} f_{B P C}
$$

where the $v_{d c, B P C}, f_{B P C}$ are measured by local sensors of BPC. And according to the dc network and ac network relation, the $v_{d c, B P C}$ and $f_{B P C}$ are expressed as

$$
\begin{aligned}
v_{d c, B P C} & =v_{d c, 0}-\frac{P_{B P C}}{v_{d c, 0}} \cdot r_{B P C}, \\
f_{B P C} & =\frac{1}{M} \sum_{i=1}^{M} f_{i} .
\end{aligned}
$$

Linearizing the equation (41)-(43), and combining the linearized interaction power equation (40), we have

$$
\begin{gathered}
\Delta \dot{v}_{d c}=-\omega_{v d c} \Delta v_{d c}+J X_{D C}+e \Delta P_{B P C}, \\
\Delta f=-\omega_{f} \Delta f+G X_{A C}, \\
\Delta P_{B P C}=-\frac{e k_{P}}{w} \Delta P_{B P C}+\left(\frac{k_{I}-k_{P} \omega_{v d c}}{w}\right) \Delta v_{d c}+\left(\frac{-k_{I}+k_{P} \omega_{f}}{m}\right) \Delta f- \\
\frac{k_{P}}{m} G X_{A C}+\frac{k_{P}}{w} J X_{D C},
\end{gathered}
$$

\section{Hybrid AC/DC Microgrid Model and the Stability Analysis}

Combining the ac subgrid model in (34), dc subgrid model in (39), and BPC mode in (44)-(46), the small signal model of hybrid ac/dc microgrid is gotten as

$$
\dot{X}=K X \text {. }
$$

where $X=\left[\begin{array}{lllll}X_{A C} & X_{D C} & \Delta P_{B P C} & \Delta v_{d c} & \Delta f\end{array}\right]$,

The stability of the hybrid ac/dc microgrid with significant control parameters can be analyzed through the locus of eigenvalues of matrix $K$ in (47). For a typical hybrid microgrid in Fig. 11 with parameters in Table II, the cutoff frequency $\omega_{f}$ of low-pass filter for ac subgrid frequency, the cutoff frequency $\omega_{v d c}$ of low-pass filter for dc subgrid voltage, and the PI controller parameter $k_{P}, k_{I}$ for BPC are studied in Fig. 9. The hybrid microgrid operate in mode I, and no DGs reaches the maximum power in this subsection.

In Fig. 9 (a), the cutoff frequency $\omega_{f}$ of ac subgrid frequency filter increases from $1 \mathrm{rad} / \mathrm{s}$ to $50 \mathrm{rad} / \mathrm{s}$, two dominant pole move towards to the imaginary axis, and one dominant pole moves backward, the stability of the hybrid microgrid firstly increases and then decreases. In Fig. 9 (b), the cutoff frequency $\omega_{v d c}$ of dc subgrid voltage filter increases from $1 \mathrm{rad} / \mathrm{s}$ to 50 $\mathrm{rad} / \mathrm{s}$, the main dominant poles move opposite to the imaginary axis, which means the stability gets increased with the $\omega_{v d c}$ increasing. In Fig. 9 (c), the proportional parameter $k_{P}$ increases from 50 to 1500 with $k_{i}=100 k_{P}$, the stability of the hybrid microgrid firstly increases and then degrades, the dynamic response becomes faster with the increasing of the imaginary part of the conjugate poles.

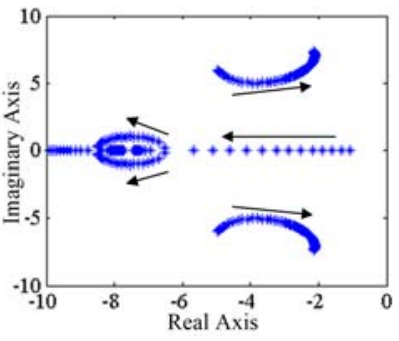

(a)

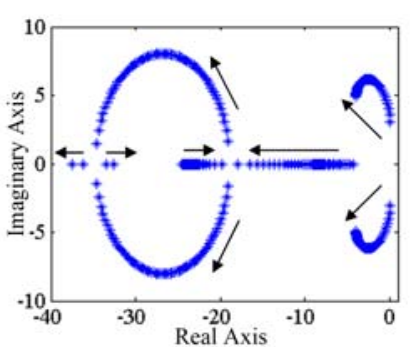

(b)

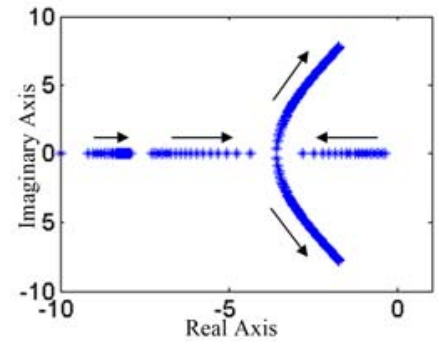

(c)

Fig. 9. Dominant poles of the small signal model with different control parameters.

From the above analysis, the influence of the significant control parameters can be embodied by the eigenvalues locus in Fig. 9. The $\omega_{f}$ is more sensitive than $\omega_{v d c}$, and the stability and response speed should be traded off when setting the $k_{P}, k_{I}$. The global stability can be ensured by appropriate controller setting.

\section{E. The Stability Analysis Along with Different Load Conditions in Different Modes}

For the tradition droop control, the load will be shared by DGs according to their capacities, and all DGs will reach their maximum power simultaneously when the load power reaches the DGs' total maximum power. However, for the proposed economic operation control, the load is shared according to the DGs' nonlinear incremental costs. The DGs will reach the maximum power successively with the load power increasing. When one DG reaches the maximum power, the mode will change correspondingly as shown in Fig. 6, and this DG cannot share more load to balance the power demand, which may endanger the stability of the system. Therefore, the stability analysis along with different operation points in different modes is necessary. When one DG reaches the maximum power, the DG can be regard as an undispatchable DG with invariable output power. Hence, the small signal models of hybrid microgrid in different modes can still be depicted in (47) with a different subgrid's state space $X_{A C}$ or $X_{D C}$. The analysis result is shown in Fig. 10. From the result, the hybrid microgrid is stable with the large operation points in different modes, and the stability will decrease with the load increasing in high load modes (mode IV and mode V)

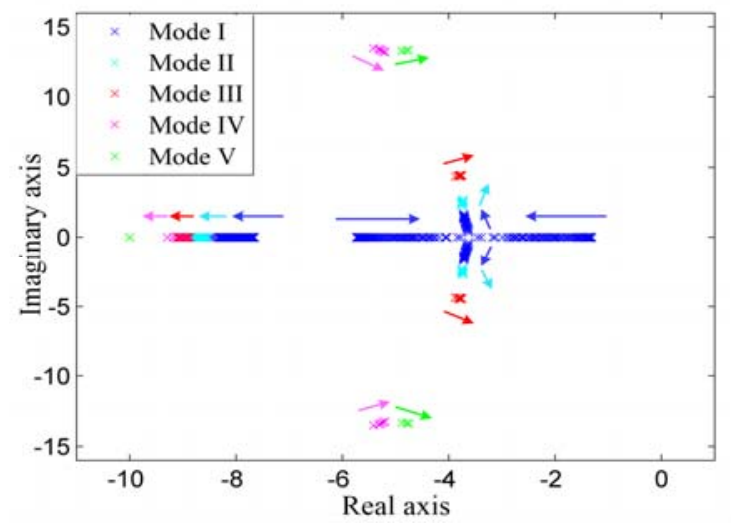

Fig. 10. Dominant poles of the hybrid microgrid system along with the increasing of load in different modes. 
V. HARDWARE-IN-LOOP TESTS

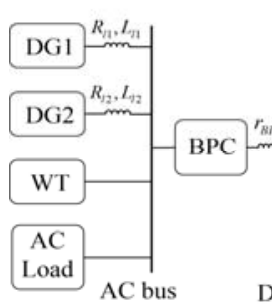

(a)

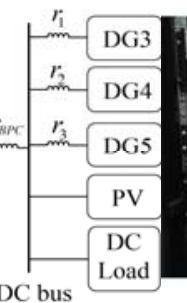

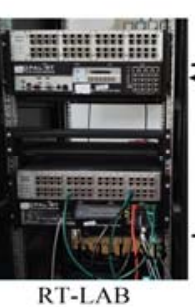

RT-LAB

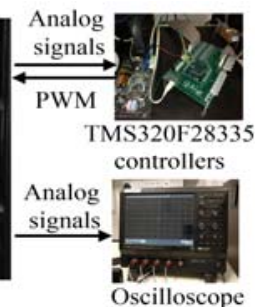

(b)
Fig.11. HIL platform setup. (a) Studied hybrid ac/dc microgrid system. (b) HIL test facilities.

To evaluate the effects of the proposed economic operation control, the hard-in-loop (HIL) tests are conducted using RTLAB and STM32F407MCUs as shown in Fig. 11(b). The tested hybrid microgrid is shown in Fig. 12(a), which contains DG1 and DG2 in ac subgrid, DG3, DG4 and DG5 in dc subgrid, renewable DGs like PV or WT in ac and dc subgrids. The detailed parameters of the hybrid microgrid are listed in Table III.

TABLE III

PARAMETERS OF THE HYBRID MICROGRID

\begin{tabular}{cc}
\hline \hline Microgrid Parameters & Rated Values \\
\hline AC bus voltage $V^{*} / f^{*}$ & $380 \mathrm{~V} / 50 \mathrm{~Hz} \pm 0.5 \mathrm{~Hz}$ \\
DC bus voltage $v_{d c}^{*}$ & $600 \mathrm{~V} \pm 30 \mathrm{~V}$ \\
AC load & $300 \mathrm{~kW} / 100 \mathrm{kVar}$ \\
DC load & $450 \mathrm{~kW}$ \\
WT maximum power & $150 \mathrm{~kW} / 50 \mathrm{kVar}$ \\
PV maximum power & $200 \mathrm{~kW}$ \\
DG1 line impedance $R_{l 1} / L_{l 1}$ & $2 \mathrm{~m} \Omega / 1.5 \mathrm{mH}$ \\
DG2 line impedance $R_{l 2} / L_{l 2}$ & $1 \mathrm{~m} \Omega / 1.2 \mathrm{mH}$ \\
DC line impedances $r_{1} / r_{2} / r_{3} / r_{B P C}$ & $6 / 4 / 3 / 4(\mathrm{~m} \Omega)$ \\
\hline
\end{tabular}

\section{A. Economic operation test with load changing}

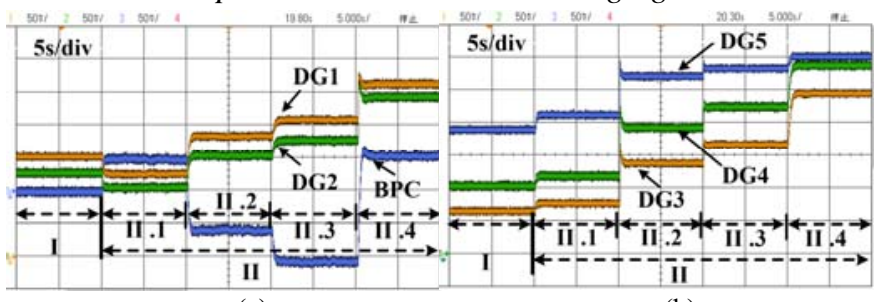

(a)

(b)

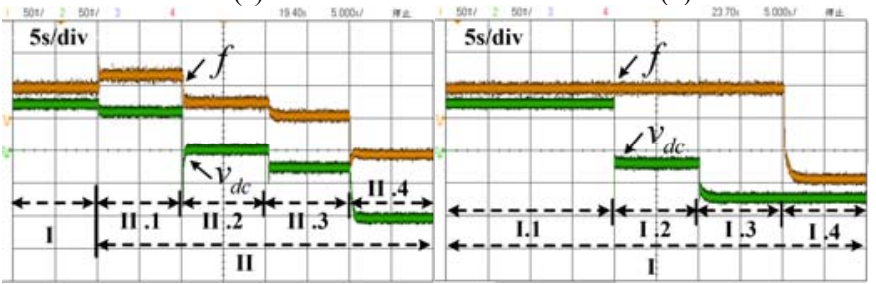

(c)

(d)

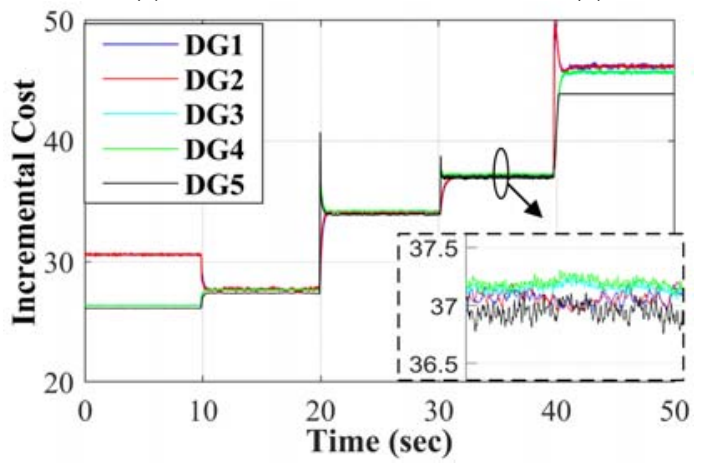

(e)

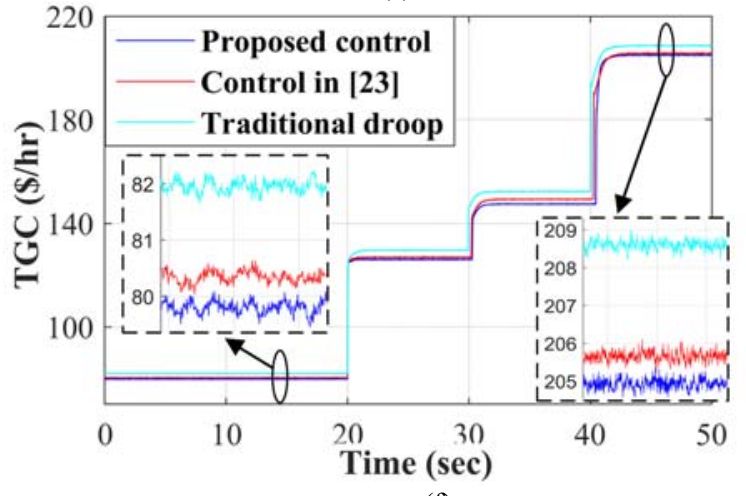

(f)

Fig. 12. Dynamics of the system when the load power changes. (a) Output active power of DG1, DG2 and BPC (25kW/div). (b) Output power of DG3, DG4 and DG5 (25kW/div). (c) Frequency and dc voltage variation with the economic power interaction control $(0.167 \mathrm{~Hz} / \mathrm{div})(10 \mathrm{~V} / \mathrm{div})$. (d) Frequency and dc voltage variation without the power interaction control. (e) Incremental costs of DGs in the dynamic process. (f) TGC of hybrid microgrid with different control strategies.

Fig. 12 shows the system dynamics when the load power changes. The output power of PV and WT remains invariable in the dynamic process. In state I, the subgrid economic control strategy is adopted individually for ac subgrid and dc subgrid, then BPC is put into operation in state II, and both the subgrids and BPC control strategy are adopted. In state II, three load power step changes are introduced. First, the output power of dc load power increases from $240 \mathrm{~kW}$ to $390 \mathrm{~kW}$ in state II.2. Then, the dc load power increases to the dc maximum power $450 \mathrm{~kW}$ in state II.3. Finally, the ac load active power increases from $160 \mathrm{~kW}$ to the ac maximum power $300 \mathrm{~kW}$ in state II.4.

Fig. 12 (a) shows the power fluctuations of the DG1, DG2 and BPC, and Fig. 12 (b) shows the power fluctuation of the DG3, DG4 and DG5. In the state I, the BPC is cut out, and the ac and dc subgrid operate independently with no power interaction. In state II, the BPC is put into operation, then the dc load power increment is shared by the DGs in both ac and dc subgrids in state II.2 and state II.3. In those two dynamic processes, the BPC power injected into the ac subgrid is decreased, and the output power of all DGs get increased. In state II.4, the ac load power increment is shared by all DGs, and the BPC power injected to the ac subgrid is increased. The DG5 reaches the maximum power of $150 \mathrm{~kW}$, and the hybrid microgrid changes from mode I to mode II.

Fig. 12 (c) shows the dynamic process of ac subgrid frequency and dc subgrid voltage with the economic power interaction control. In the state II, when the load power steps in any subgrid, the ac frequency and dc voltage will response synchronously, which means the two subgrids can coordinate with each other to share the power fluctuation together with the $\mathrm{BPC}$ control strategy. The frequency and de voltage variation is $50.21 \mathrm{~Hz}$ to $49.82 \mathrm{~Hz}$ and $611 \mathrm{~V}$ to $580 \mathrm{~V}$. Fig. 12 (d) shows ac frequency and dc bus voltage without the power interaction control. From the scope, the dc load steps have no influence on the frequency in state I.2 and state I.3; the ac load step does not affect the dc voltage in the state I.4. The load power fluctuation in one subgrid is not shared by the other subgrid, and the subgrids cannot operate collaboratively.

Fig. 12 (e) shows the incremental costs of all DGs in the dynamic process. In state I, the incremental costs of DGs in the same subgrid are identical, which means the economic 
operation of individual subgrid is realized. In state II.1, the economic power interaction control is adopted, and the incremental costs of DGs in two subgrids get equal. According to the equal incremental cost principle, the TGC of the hybrid microgrid is minimum in this situation. In state II.2 and state II.3, the incremental costs increase uniformly with the load power increases. In state II.4, the incremental cost of DG5 get maximal and less than the other DGs in mode II. The other DGs' incremental costs are still equal, and the economic operation of hybrid microgrid is still realized.

Fig. 12 (f) shows the comparison results of TGC of hybrid microgrid with different control strategies. The zoom in scopes are also given in Fig. 12 (f). The quantitative results between the proposed control and other decentralized control are compared in Tables IV and V. The power sharing and the incremental costs of the DGs, the interaction power of the BPC and the TGC of the hybrid microgrid in State II.2 and State II.3 are listed respectively. For the traditional droop control, the load is shared according to the DGs' capacities without considering generation costs. Hence, the TGC is much higher with the unequal incremental costs of the DGs. With the proposed control in this paper, the economic power sharing and power interaction is realized, and the TGC of the hybrid microgrid is minized with the identical incremental costs. Compared with the control in [23] under the same condition, the proposed control can balance the incremental costs of the DGs in different subgrids, which can further reduce the TGC than the control in [23].

\section{TABLE IV}

COMPARISON OF THE RESULTS IN STATE II.2 WITH DIFFERENT CONTROLS

\begin{tabular}{cccc}
\hline \hline $\mathrm{DG}_{i}$ & $\begin{array}{c}\text { Traditional } \\
\text { Droop Control }\end{array}$ & $\begin{array}{c}\text { Control } \\
\text { In [23] }\end{array}$ & $\begin{array}{c}\text { Proposed } \\
\text { Control }\end{array}$ \\
\hline$P_{D G 1} / \lambda_{D G 1}$ & $70.1 \mathrm{~kW} / 29.26$ & $98.1 \mathrm{~kW} / 35.54$ & $91.6 \mathrm{~kW} / 34.00$ \\
$P_{D G 2} / \lambda_{D G 2}$ & $70.1 \mathrm{~kW} / 32.18$ & $83.0 \mathrm{~kW} / 35.52$ & $77.2 \mathrm{~kW} / 34.01$ \\
$P_{D G 3} / \lambda_{D G 3}$ & $109.4 \mathrm{~kW} / 42.87$ & $63.9 \mathrm{~kW} / 33.08$ & $68.4 \mathrm{~kW} / 34.05$ \\
$P_{D G 4} / \lambda_{D G 4}$ & $110.3 \mathrm{~kW} / 36.60$ & $91.5 \mathrm{~kW} / 33.11$ & $96.8 \mathrm{~kW} / 34.06$ \\
$P_{D G 5} / \lambda_{D G 5}$ & $110.8 \mathrm{~kW} / 27.94$ & $134.1 \mathrm{~kW} / 33.10$ & $136.4 \mathrm{~kW} / 34.05$ \\
$P_{B P C}$ & $0 \mathrm{~kW}$ & $-41.1 \mathrm{~kW}$ & $-28.7 \mathrm{~kW}$ \\
$\mathrm{TGC}$ & 129.4 & 126.1 & 125.8 \\
\hline
\end{tabular}

TABLE V

COMPARISON OF THE RESULTS IN STATE II.3 WITH DIFFERENT CONTROLS

\begin{tabular}{cccc}
\hline \hline $\mathrm{DG}_{i}$ & $\begin{array}{c}\text { Traditional } \\
\text { Droop Control }\end{array}$ & $\begin{array}{c}\text { Control } \\
\text { In [23] }\end{array}$ & $\begin{array}{c}\text { Proposed } \\
\text { Control }\end{array}$ \\
\hline$P_{D G 1} / \lambda_{D G 1}$ & $70.1 \mathrm{~kW} / 29.26$ & $114.9 \mathrm{~kW} / 40.02$ & $104.3 \mathrm{~kW} / 37.07$ \\
$P_{D G 2} / \lambda_{D G 2}$ & $70.1 \mathrm{~kW} / 32.18$ & $100.1 \mathrm{~kW} / 40.02$ & $89.0 \mathrm{~kW} / 37.08$ \\
$P_{D G 3} / \lambda_{D G 3}$ & $129.3 \mathrm{~kW} / 47.21$ & $73.9 \mathrm{~kW} / 35.23$ & $82.4 \mathrm{~kW} / 37.05$ \\
$P_{D G 4} / \lambda_{D G 4}$ & $130.3 \mathrm{~kW} / 41.02$ & $103.2 \mathrm{~kW} / 35.24$ & $112.7 \mathrm{~kW} / 37.07$ \\
$P_{D G 5} / \lambda_{D G 5}$ & $130.9 \mathrm{~kW} / 31.99$ & $138.9 \mathrm{~kW} / 35.23$ & $142.1 \mathrm{~kW} / 37.08$ \\
$P_{B P C}$ & $0 \mathrm{~kW}$ & $-74.8 \mathrm{~kW}$ & $-53.2 \mathrm{~kW}$ \\
$\mathrm{TGC}$ & 152.0 & 147.9 & 147.1 \\
\hline
\end{tabular}

Compared with TGC of the traditional droop control, the TGC reduction of the proposed economic control strategies in different ac and dc load factors are listed in Table VI. When there is a relative larger difference between the ac load and dc load factors, more economic power interaction will be transmitted via BPC as Fig. 7 shown, and as a result the TGC reduction will be more obvious in Table VI.

TABLE VI

TGC REDUCTION WITH DIFFERENT AC AND DC LOAD FACTORS

\begin{tabular}{c|cccc}
\hline AC load & $25 \%$ & $50 \%$ & $75 \%$ & $100 \%$ \\
\hline $25 \%$ & $1.68 \%$ & $4.69 \%$ & $10.75 \%$ & $18.16 \%$ \\
$50 \%$ & $3.87 \%$ & $2.44 \%$ & $4.89 \%$ & $9.82 \%$ \\
$75 \%$ & $6.53 \%$ & $2.50 \%$ & $1.97 \%$ & $4.04 \%$ \\
$100 \%$ & $9.35 \%$ & $3.58 \%$ & $2.42 \%$ & $0 \%$ \\
\hline \hline
\end{tabular}

\section{B. Economic operation test with time-varying output power of} renewable DGs

Fig. 13 shows the system dynamics with the renewable DGs' output power varying. In this test, there are two kinds of renewable DGs, a WT in the ac subgrid, and a PV in the dc subgrid. The output power diagram of PV and WT is shown in Fig. 13 (a) and Fig. 13 (b). According to the variation of PV output power, the dynamic of the system is divided into three stages. In state I and state III, the output power of PV remains 0 to simulate the night time. In state II, the output power of PV increases to the maximum power, and then reduce to 0 . The load power remains invariable in this test.

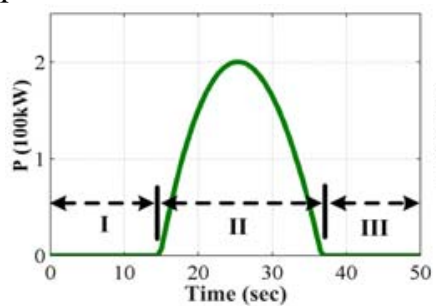

(a)

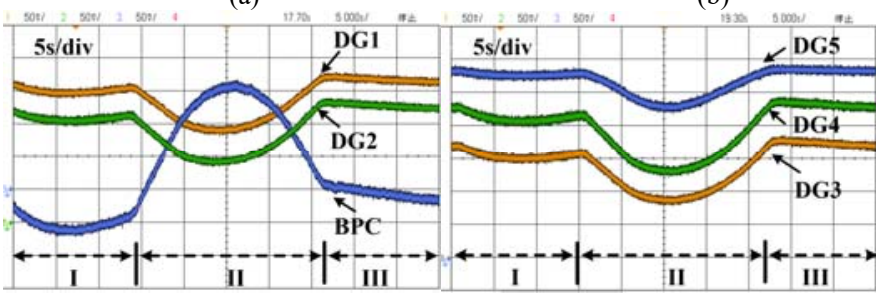

(c)

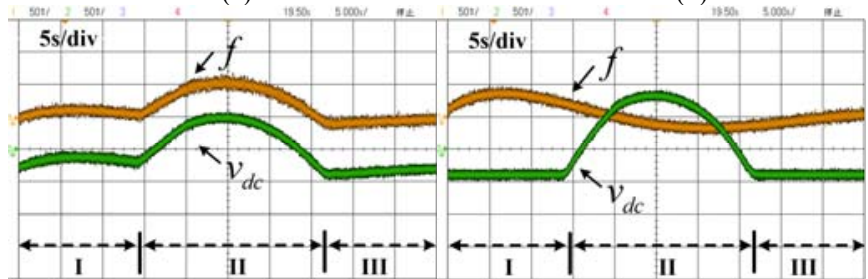

(e)

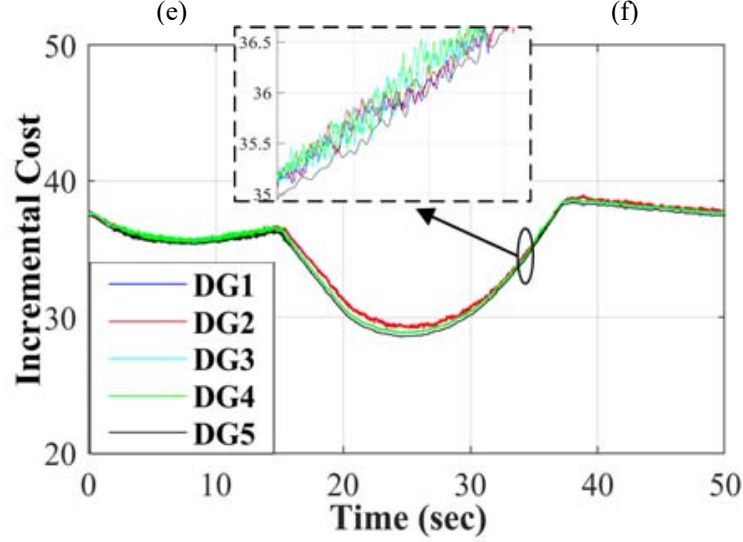

(g) 


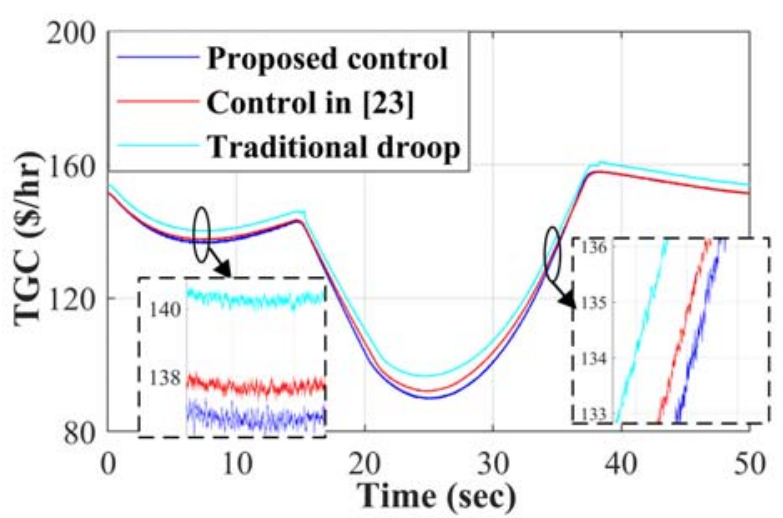

(h)

Fig. 13. Dynamics of the system when the renewable DGs' output power varies. (a) Output power variation of $\mathrm{PV}$ in the de subgrid. (b) Output power variation of WT in the ac subgrid. (c) Output active power of DG1, DG2 and BPC (25kW/div). (d) Output power of DG3, DG4 and DG5 (25kW/div). (e) Frequency and dc voltage variation with the BPC control strategy $(0.167 \mathrm{~Hz} / \mathrm{div})$ (10V/div). (f) Frequency and dc voltage variation without the economic power interaction. (g) Incremental cost of DGs (h) TGC of hybrid microgrid with different control strategies.

Fig. 13 (c) and (d) shows the power fluctuations of DG1, DG2, BPC and DG3, DG4 and DG5 with the proposed control. In the state I and state III, only the output power of WT is varying. From the scope, all the five DGs' output power is changing synchronously, which means the power fluctuation of WT in the ac subgrid is shared by the DGs in both ac and dc subgrids. The power sharing proportions are shown in Fig.6. In the state II, there is a large power fluctuation of PV in the dc subgrid. All the DGs share the power fluctuation together. Besides, the BPC power injected into the ac subgrid is increased when the PV power increases, and decreased when the PV power decreases, which shows the two subgrids can coordinate with each other.

Fig. 13 (e) shows the dynamic process of ac subgrid frequency and dc subgrid voltage with the proposed economic power interaction control. The two subgrids can operate coordinately via the BPC. From the scope, the ac frequency and dc voltage change together with the fluctuation of sum power consisted by the WT and PV. The frequency and dc voltage variation is $50.17 \mathrm{~Hz}$ to $49.97 \mathrm{~Hz}$ and $609 \mathrm{~V}$ to $592 \mathrm{~V}$. Fig. 13 (f) shows the frequency and the voltage without the power interaction control. The two subgrids operate separately. In the ac subgrid, the frequency changes only with the WT power; and in the dc subgrid, the dc voltage varies only with the PV power. The frequency and dc voltage variation is $50.14 \mathrm{~Hz}$ to $49.95 \mathrm{~Hz}$ and $616 \mathrm{~V}$ to $592 \mathrm{~V}$. Comparing the two scopes, the ranges of frequency are approximate, while, the range of dc voltage in Fig. 13 (e) is much smaller than the voltage range in Fig. 13 (f). It shows that by adopting the BPC control strategy, the coordination between the two subgrids can reduce the total deviations of the two subgrids, and improve the overall power quality of the hybrid microgrid.

Fig. 13 (g) shows the incremental costs of all DGs with the proposed subgrid and BPC strategies. The five incremental costs get identical, and vary with their output power. According to the equal incremental cost principle, the TGC of the hybrid microgrid is minimum in this situation. The detailed TGC comparison of different control strategies is given in Fig. 13 (h). When the output power of WT and PV is varying, the TGC with the proposed subgrid and BPC control strategies is always minimal in this dynamic process, and the economic operation is realized.

\section{CONCLUSION}

In this paper, a decentralized economic operation control, which consists of economic power sharing and economic power interaction between subgrids, is designed for the hybrid ac/dc microgrid. The TGC of the hybrid ac/dc microgrid is minimized, and the two subgrids can coordinate with each other. With the proposed nonlinear droop control, the hybrid ac/dc microgrid is stable in different load conditions and all modes. Verified by the real-time HIL test, the proposed control is effective for economic power sharing and economic power interaction.

\section{APPENDIX}

The detailed matrices of hybrid ac/dc microgrid model in Section IV are listed below.

$$
\begin{aligned}
& M_{i}=\left[\begin{array}{cc}
A_{i}+C_{i} I_{i} K & C_{i} V_{i} \\
B_{i} & D_{i}
\end{array}\right] \text {, } \\
& A_{i}=\left[\begin{array}{ccc}
-\omega_{a c} & 0 & 0 \\
\frac{l_{q i}}{k_{d i} l_{q i}-k_{q i} l_{d i}} & \frac{k_{q i} l_{d i} \omega_{a c}}{k_{d i} l_{q i}-k_{q i} l_{d i}} & \frac{k_{q i} l_{q i} \omega_{a c}}{k_{d i} l_{q i}-k_{q i} l_{d i}} \\
\frac{l_{d i}}{k_{q i} l_{d i}-k_{d i} l_{q i}} & \frac{k_{d i} l_{d i} \omega_{a c}}{k_{q i} l_{d i}-k_{d i} l_{q i}} & \frac{k_{d i} l_{q i} \omega_{a c}}{k_{q i} l_{d i}-k_{d i} l_{q i}}
\end{array}\right], \\
& C_{i}=\left[\begin{array}{cc}
-\frac{3}{2} m_{i} \omega_{a c} & 0 \\
0 & \frac{\frac{3}{2} n_{i} k_{q i} \omega_{a c}}{k_{d i} l_{q i}-k_{q i} l_{d i}} \\
0 & \frac{\frac{3}{2} n_{i} k_{d i} \omega_{a c}}{k_{q i} l_{d i}-k_{d i} l_{q i}}
\end{array}\right] \text {, } \\
& m_{i}=2 \pi m \cdot \frac{d \lambda_{i}\left(P_{i}\right)}{d P_{i}}, \\
& K=\left[\begin{array}{ll}
0 & 0 \\
1 & 0 \\
0 & 1
\end{array}\right]^{T}, \\
& I_{i}=\left[\begin{array}{cc}
i_{d i} & i_{q i} \\
-i_{q i} & i_{d i}
\end{array}\right] \text {, } \\
& V_{i}=\left[\begin{array}{cc}
V_{d i} & V_{q i} \\
V_{q i} & -V_{d i}
\end{array}\right] \text {, } \\
& B_{i}=\left[\begin{array}{ccc}
i_{q i} & \frac{1}{L_{l i}} & 0 \\
-i_{d i} & 0 & \frac{1}{L_{l i}}
\end{array}\right], \\
& D_{i}=\left[\begin{array}{cc}
-R_{l i} / L_{l i} & \omega_{i} \\
-\omega_{i} & -R_{l i} / L_{l i}
\end{array}\right] \text {, } \\
& N_{i}=\left[\begin{array}{lllll}
0 & 0 & 0 & -1 / L_{l i} & 0
\end{array}\right]^{T} \text {, } \\
& P=\left[\begin{array}{cccc}
M_{1}+N_{1} E_{1} & \cdots & N_{1} E_{i} & \cdots \\
\vdots & \ddots & \vdots & \ddots \\
N_{i} E_{1} & \cdots & M_{i}+N_{i} E_{i} & \cdots \\
\vdots & \ddots & \vdots & \ddots
\end{array}\right]_{5 M \times 5 M} \\
& E_{i}=\left[\begin{array}{lllll}
0 & a i_{d i} & a i_{q i} & a V_{d i} & a V_{d i}
\end{array}\right], \\
& Q=\left[\begin{array}{llll}
F_{1} & \cdots & F_{i} & \cdots
\end{array}\right]^{T} \text {, } \\
& F_{i}=\left[\begin{array}{lllll}
0 & 0 & 0 & -\frac{a}{L_{l i}} & 0
\end{array}\right], a=\frac{R_{a c}{ }^{2}+\left(\omega_{0} L_{a c}\right)^{2}}{3 V_{0} R_{a c}}, \\
& S=\omega_{d c} U-\operatorname{diag}\left(\omega_{d c}, \cdots, \omega_{d c}, \cdots\right)_{N \times N} \text {, } \\
& U=-2 v_{d c, 0} H^{-1} \operatorname{diag}\left(w_{1} b_{1}, \cdots, w_{j} b_{j}, \cdots\right)_{N \times N} \text {, } \\
& H=R_{d c} \cdot[1]_{N \times N}+2 \operatorname{diag}\left(r_{1}, \cdots, r_{j}, \cdots\right)_{N \times N} \text {, } \\
& w_{j}=w \cdot \frac{d \lambda_{j}\left(P_{j}\right)}{d P_{j}}, \quad b_{j}=1+\frac{r_{j} p_{j}}{v_{d c, j}^{2}}, \\
& T=\omega_{d c} R_{d c} H^{-1}[1]_{N \times 1},
\end{aligned}
$$




$$
\begin{aligned}
& J=\omega_{v d c} \cdot c\left[\begin{array}{llll}
\sum_{k=1}^{N} U_{k 1} & \cdots & \sum_{k=1}^{N} U_{k j} & \cdots
\end{array}\right]_{N \times 1}, \\
& c=\frac{R_{d c}}{2 v_{d c, 0}}\left(1+\frac{P_{B P C} \cdot r_{B P C}}{v_{d c, 0}^{2}}\right), \\
& e=\omega_{v d c}\left(\frac{c}{\omega_{a c}} \sum_{j=1}^{N} T_{j}-c-\frac{r_{B P C}}{v_{d c, 0}}\right), \\
& G=\left[\begin{array}{llll}
G_{1} & \cdots & G_{i} & \cdots
\end{array}\right]_{5 M \times 1}, \\
& G_{i}=\left[\begin{array}{lllll}
1 / 2 \pi M & 0 & 0 & 0 & 0
\end{array}\right] \text {, } \\
& K=\left[\begin{array}{ccccc}
P & 0 & Q & 0 & 0 \\
0 & S & T & 0 & 0 \\
-\frac{k_{P}}{m} G & \frac{k_{P}}{w} J & -\frac{e k_{P}}{w} & \frac{k_{I}-k_{P} \omega_{v d c}}{w} & \frac{-k_{I}+k_{P} \omega_{f}}{m} \\
0 & J & e & -\omega_{v d c} & 0 \\
G & 0 & 0 & 0 & -\omega_{f}
\end{array}\right] .
\end{aligned}
$$

\section{REFERENCES}

[1] W. Dong, H. Xin, D. Wu and L. Huang, "Small signal stability analysis of multi-infeed power electronic systems based on grid strength assessment", IEEE Trans. Power Syst. vol. 34, no. 2, pp. 1393-1403, March 2019.

[2] F. Katiraei, R. Iravani, N. Hatziargyriou and A. Dimeas, "Microgrids management", IEEE Power Energy Mag., vol. 6, no. 3, pp. 54-65, May 2008.

[3] F. Katiraei, M. R. Iravani, "Power management strategies for a microgrid with multiple distributed generation units", IEEE Trans. Power Syst., vol. 21, no. 4, pp. 1821-1831, Nov. 2006.

[4] X. Chen, Y. Hou, and S. Y. R. Hui. "Distributed control of multiple electric springs for voltage control in microgrid", IEEE Trans. Smart Grid, vol.8, no.3, pp. 1350-1359, May. 2017

[5] T. Dragicevic, X. Lu, J. Vasquez, J. Guerrero, "DC microgrids-part I: A review of control strategies and stabilization techniques", IEEE Trans. Power Electron., vol. 31, no. 7, pp. 4876-4891, Jul. 2015.

[6] H. Cai, J. Xiang and W. Wei, "Decentralized coordination control of multiple photovoltaic sources for DC Bus voltage regulating and power sharing", IEEE Trans. Ind. Electron., vol. 65, no. 7, pp. 5601-5610, July 2018.

[7] C. Jin, P. Wang, J. Xiao, Y. Tang and F. H. Choo, "Implementation of hierarchical control in DC microgrids", IEEE Trans. Ind. Electron., vol. 61, no. 8, pp. 4032-4042, Aug. 2014.

[8] X. Liu, P. Wang and P. C. Loh, "A Hybrid AC/DC microgrid and its coordination control", IEEE Trans. Smart Grid, vol. 2, no. 2, pp. 278-286, June 2011.

[9] N. Eghtedarpour and E. Farjah, "Power control and management in a hybrid AC/DC microgrid", IEEE Trans. Smart Grid, vol. 5, no. 3, pp. 14941505, May 2014.

[10]Y. Xia, Y. Peng, P. Yang, M. Yu and W. Wei, "Distributed coordination control for multiple bidirectional power converters in a hybrid $\mathrm{AC} / \mathrm{DC}$ microgrid", IEEE Trans. Power Electron., vol. 32, no.6, pp. 4949 - 4959, Jun. 2017.

[11]G. Tsikalakis and N. D. Hatziargyriou, "Centralized control for optimizing microgrids operation", IEEE Trans. Energy Convers., vol. 23, no. 1, pp. 241-248, Mar. 2008.

[12]M. E. Khodayar, M. Barati and M. Shahidehpour, "Integration of high reliability distribution system in microgrid operation", IEEE Trans. Smart Grid, vol. 3, no. 4, pp. 1997-2006, Dec. 2012.

[13]A. Askarzadeh, "A memory-based genetic algorithm for optimization of power generation in a microgrid", IEEE Trans. Sustain. Energy, vol. 9, no. 3, pp. 1081-1089, July 2018.

[14]N. Pogaku, M. Prodanovic, T. C. Green, W. L. Kling and L. V. D. Sluis, "Model-ing analysis and testing of autonomous operation of an inverterbased micro-grid", IEEE Trans. Power Electron., vol. 22, no. 2, pp. 613625, Mar. 2007.

[15]U. Nutkani, P. Loh, P. Wang and F. Blaabjerg, "Cost-prioritized droop schemes for autonomous AC microgrids", IEEE Trans. Power Electron., vol. 30, no. 2, pp. 1109-1119, Feb. 2015.

[16]U. Nutkani, P. Loh, P. Wang and F. Blaabjerg, "Linear decentralized power sharing schemes for economic operation of AC microgrids", IEEE Trans. Ind. Electron., vol. 63, no. 1, pp. 225-234, Aug. 2015.

[17] U. Nutkani, W. Peng, P. C. Loh and F. Blaabjerg, "Autonomous economic operation of grid connected dc microgrid", Proc. IEEE 5th Int. Symp. Power Electron. Distrib. Gener. Syst., pp. 1-5, Jun. 2014.

[18]P. Yang, Y. Xia, M. Yu, W. Wei and Y. Peng, "A Decentralized coordination control method for parallel bidirectional power converters in a hybrid AC/DC microgrid", IEEE Trans. Ind. Electron., vol. 65, no. 8, pp. 6217-6228, Aug. 2018.

[19]N. Nikmehr and S. N. Ravadanegh, "Optimal power dispatch of multimicrogrids at future smart distribution grids", IEEE Trans. Smart Grid, vol. 6, no. 4, pp. 1648-1657, Jul. 2015.

[20]Q. Zhou, M. Shahidehpour, Z. Li and X. Xu, "Two-layer control scheme for maintaining the frequency and the optimal economic operation of hybrid AC/DC microgrids", IEEE Trans. Power Syst., vol. 34, no. 1, pp. 64-75, Jan. 2019.

[21]T. Lu, Z. Wang, Q. Ai and W. J. Lee, "Interactive model for energy management of clustered microgrids", IEEE Trans. Ind. Appl., vol. 53, no 3, pp. 1739-1750, May. 2017.

[22] Y. Zhang, Y. Liang, Z. Xu, L. Li and P. Yang, "Multi-timescale optimization strategy for three-phase/single-phase multi-microgrids", Proc. 47th IEEE Ind. Electron. Soc. Annu. Conf., Beijing, 2017, pp. 62916297.

[23] Q. Xu, J. Xiao, P. Wang and C. Wen, "A decentralized control strategy for economic operation of autonomous $\mathrm{AC}, \mathrm{DC}$, and hybrid $\mathrm{AC} / \mathrm{DC}$ microgrids", IEEE Trans. Energy Convers., vol. 32, no. 4, pp. 1345-1355, Dec. 2017.

[24] A. J. Wood, B. F. Wollenberg, Power Generation Operation and Control, New York:Wiley-Interscience, 1996.

[25]D. B. Das, C. Patvardhan, "New multi-objective stochastic search technique for economic load dispatch", Proc. Inst. Elect. Eng. Gen. Transm. Distrib., vol. 145, no. 6, pp. 747-752, 1998.

[26] K. D. Brabandere, B. Bolsens, J. V. D. Keybus, A. Woyte, J. Driesen and R. Belmans, "A voltage and frequency droop control method for parallel inverters", IEEE Trans. Power Electron., vol. 22, no. 4, pp. 1107-1115, Jul. 2007. 